\title{
OPTIMALISASI PERFORMANCE REPRODUKSI DAN ADOPSI INOVASI UREA MOLASES BLOCK (UMB) PADA KELOMPOK PETERNAKAN SAPI MAKMUR KECAMATAN PAUH KOTA PADANG
}

\author{
Ediset, Jaswandi, Rusmana, Edwin Heriyanto, Amrizal Anas dan Basril Basyar \\ Fakultas Peternakan, Universitas Andalas Padang \\ Email: edisetjami80@gmail.com
}

Received : 24 Juni 2018. Accepted : 30 Juli 2018. Published Online 7 September 2018

\begin{abstract}
ABSTRAK
Tujuan kegiatan ini adalah untuk: 1) meningkatkan pengetahuan dan keterampilan peternak tentang performance reproduksi, dan 2) meningkatkan pengetahuan dan keterampilan peternak dalam membuat pakan ternak Urea Molases Block (UMB), serta 3) menumbuhkan semangat kewirausahaan di bidang peternakan sapi. Sasaran dari kegiatan ini adalah anggota kelompok peternak sapi Makmur dan peternak lain yang bukan anggota kelompok serta Penyuluh Pertanian yang memilki wilayah kerja di lokasi kegiatan. Metode yang diterapkan dalam kegiatan ini adalah metode penyuluhan dengan beberapa pendekatan, yaitu metode ceramah/sosialisasi, kunjungan rumah dan usahatani serta metode demonstrasi. Pendekatan ceramah/sosialisasi dipakai pada waktu penyampaian materi yang berkaitan dengan semangat kewirausahaan, dan pendekatan kunjungan rumah di lakukan untuk menyampaian materi yang berkaitan dengan performace reproduksi, sedangkan pendekatan penyuluhan demonstrasi diterapkan pada kegiatan introduksi inovasi pakan Urea Molases Block (UMB). Hasil dari kegiatan ini menunjukan bahwa partisipasi sasaran kegiatan begitu tinggi terhadap kegiatan yang dilakukan oleh tim karena disamping anggota kelompok yang hadir juga hadir peternak lain, penyuluh dan bahkan mahasiswa peternakan yang sedang melakukan Farm Experience, serta pada sesi diskusi banyak pertanyaan yang muncul terkait dengan materi yang paparkan oleh narasumber dan bahkan pada beberapa aspek terjadi diskusi yang cukup mendalam. Gambaran partisipasi kegiatan tersebut sejalan dengan perubahan perilaku yang terjadi pada sasaran kegiatan, terutama perubahan pada aspek koqnitif dan perubahan pada aspek physikomotorik, dimana pada aspek koqnitif peternak mengetahui potensi ekonomi usaha peternakan sapi serta mengetahui dan terampil mengatur reproduksi ternak terutama setelah induk melahirkan anak, serta terampil cara membuat UMB dan cara memberikan UMB pada ternak sapi yang dipelihara.
\end{abstract}

Kata kunci: semangat kewirausahaan, pengaturan reproduksi, urea mineral block (UMB)

\section{Optimization of Reproduction Performance and Adoption of Innovation Urea Molases Block (UMB) at Makmur Cattle Farm Group Pauh District, Padang}

\begin{abstract}
The purpose of this activity is to: 1) increase knowledge and skills of breeders on reproduction performance, and 2) to increase knowledge and skills of farmers in making Urea Molases Block (UMB) feed, and 3) to grow entrepreneurship spirit in the field of animal husbandry cow. The goal of community service activities is the members of the Makmur cattle breeder group and other breeders who are not members of the group and Agricultural Extension workers who have a working area in the location of devotional activities. The method applied in this devotional activity is the method of counseling with several approaches, namely lecture / socialization method, home visit and farming and demonstration methods. The lecture / socialization approach is used at the time of delivery of materials related to entrepreneurial spirit, and the home visit approach is done to deliver materials related to reproductive performance, while the demonstration extension approach is applied to the introduction of Urea Molases Block (UMB) feed innovation. The result of the community service activity shows that the participation of the target of the activity of high service to the activity done by the team of dedication because besides the group members who attended also present other breeders, extension workers and even farm students who are doing Farm Experience, as well as on the discussion session many questions appear related to the material presented by the resource person and even on some aspects of the discussion are quite deep. The description of the participation of the activity is in line with the behavior change that occurs on the target of the activity, especially the change in the coqnitive aspect and the change in the physikomotoric aspect,
\end{abstract}


where in the aspect koqnitif the breeder knows the economic potential of the cattle breeding business and knows and skillfully arranges the reproduction of livestock especially after the mother gives birth to the child, skilled way of making UMB and how to give UMB to cattle raised.

Keywords: entrepreneurship spirit, reproduction arrangement, urea mineral block (UMB)

\section{PENDAHULUAN}

Pembangunan sub sektor peternakan memberikan harapan peluang keberhasilan yang besar dimasa yang akan datang, hal ini disebabkan oleh meningkatnya permintaan akan produk peternakan. Kondisi ini seyogya akan berbanding lurus dengan tingkat kesejahteraan peternak karena permintaan terhadap produk peternakan yang juga cendrung meningkat, sesuai dengan prinsip ekonomi semakin banyak permintaan maka semakin tinggi harga yangg ditawarkan sehingga pendapatan peternak juga akan meningkat. Peternak yang tergabung dalam satu kelompok peternak mempunyai posisi tawar yang lebih baik dibandingkan dengan peternak yang mengelola usahanya sendiri karena disamping dapat menjalankan usaha secara bersama juga dapat mengakses berbagai jenis akomodasi dari instansi terkait sehingga dengan hal tersebut peluang untuk berkembang dan majunya suatu kelompok usaha peternakan akan lebih cepat.

Kelompok usaha peternakan Makmur merupakan sala satu kelompok ternak sapi potong yang sudah melakukan sistem pemeliharaan secara intensif, dimana kelompok ini terdapat di Koto Baru, Kelurahan Limau Manis Selatan, Kecamatan Pauh Kota Padang, jarak kelompok peternak sapi Makmur ini dari Universitas Andalas adalah \pm 10 KM. Kelompok usaha Peternakan Ternak Makmur merupakan kelompok baru dengan sebagian besar anggotanya adalah anggota lama, munculnya kelompok ini diinisiasi oleh seorang anggota lama yang bernama Jamaris Sidik, atas prakarsa dia maka dibentuklah kelompok baru yang khusus bergerak dibidang usaha peternakan sapi, jenis ternak sapi yang diusahakan adalah sapi simental, sapi limausin, sapi pesisir, sapi PO dan bahkan sapi bali, kelompok ini memiliki anggota sebanyak 13 orang, dengan jumlah ternak yang dipelihara \pm 30 ekor.

Kondisi kelompok ini berdasarkan hasil penelusuran awal adalah usaha peternakan yang dijalankan oleh anggota kelompok masih sebatas usaha sambilan sehingga tujuan usaha hanya untuk memperoleh tambahan penghasilan saja, pengetahuan pada aspek teknis belum sama untuk semua anggota, pengetahuan tentang inovasi masih rendah dan adopsi inovasi juga masih kurang, baik itu inovasi yang terkait dengan aspek pakan maupun pada aspek reproduksi ternak.

Keberadaan potensi daerah di lokasi usaha peternakan sapi Makmur tersebut selayaknya didukung pula oleh perubahan orientasi tujuan usaha, peningkatan pengetahuan baik pada aspek teknis maupun tentang performace reproduksi dan penerapan inovasi. Rogers dan Shoemaker (1995) mengartikan inovasi sebagai: ide-ide baru, praktek-praktek baru, atau obyek-obyek yang dapat dirasakan sebagai sesuatu yang baru oleh individu atau masyarakat. Inovasi peternakan itu selain inovasi pada bidang reproduksi juga terdapat inovasi pada aspek pakan itu sendiri, seperti inovasi teknologi pakan Urea Molases Block (UMB).

Berdasarkan uraian diatas dapat dikemukakan masalah yang dihadapi para peternak sapi di kelompok usaha peternakan sapi "Makmur", di Kelurahan Limau Manis Selatan, Kecamatan Pauh Kota Padang adalah : 
1. Bagaimana meningkatkan motivasi peternak untuk mengembangkan usaha peternakan sehingga usaha yang dilakukan menjadi pekerjaan utama.

2. Bagaimana meningkatkan pengetahuan dan keterampilan peternak tentang performance reproduksi.

3. Bagaimana meningkatkan keterampilan peternak dalam membuat pakan sendiri seperti Urea Molases Block (USB)

\section{METODE}

\section{Penyuluhan}

Metode pelaksanaan Kegiatan yang dilakukan adalah metode penyuluhan dengan menggunakan beberapa pendekatan :

1. Ceramah

Pendekatan ceramah ini dilakukan untuk merubah perilaku peternak mitra pada aspek pengetahuan (koqnitif) karena biasanya lebih mengutamakan diskusi antara narasumber dengan sasaran. Pendekatan ini sama juga dengan pendekatan pidato yang bertujuan untuk transfer ilmu melalui pemaparan materi dari sumber pada sasaran yang dilengkapi dengan sesi diskusi/tanya jawab untuk menambah pemahaman peternak terkait dengan materi yang disampaikan. Van Den Ban (1999) menambahkan bahwa pendekatan penyuluhan ceramah biasanya diikuti diskusi dengan mengajukan pertanyaan untuk menjelaskan hal hal yang penting untuk memusatkan perhatian massa pada suatu masalah.

Pada kegiatan penyuluhan ini pendekatan ceramah di pergunakan untuk menyampaikan materi yang berkaitan semangat kewirausahaan dan konsep performance reproduksi. Dalam pendekatan sosilisasi ini materi yang akan diberikan adalah:

a. Semangat kewirausahaan, materi ini perlu untuk disampaikan untuk memotivasi peternak agar merubah orientasi usaha, baik dari segi jumlah populasi maupun dari tujuan usaha itu.

b. Performace Reproduksi, topik yang disampaikan berkaitan pengaturan reproduksi induk sapi setelah melahirkan.

\section{Demonstrasi}

Metode demonstrasi diterapkan sesuai dengan jenis pesan yang mau disampaikan dalam kegiatan penyuluhan yang dilakukan, karena demonstrasi itu terdiri dari dua bagaian yaitu demonstrasi cara dan demonstrasi hasil. Anwar (2009) mengatakan bahwa ada dua macam demonstrasi, yaitu demonstrasi cara dan demonstrasi hasil. Pada kegiatan penyuluhan ini lebih banyak menggunakan metode demonstrasi cara, yaitu untuk mendeteksi tanda tanda birahi, mengatur reproduksi ternak setelah melahirkan anak dan cara membuat pakan Urea Molases Block (UMB) serta cara pemberian UMB pada Ternak sapi

\section{Pelatihan}

Metode pelatihan diterapkan pada kegiatan penyuluhan untuk membuat Urea Molases Block (UMB), dimana setelah disampaikan secara teori dan di demonstrasi, anggota kelompok dilatih membuat UMB dengan kapasitas 5 kilogram, dimana bahan bahan untuk pembuatan UMB tersebut sudah disediakan oleh tim. 


\section{Bimbingan dan Pembinaan}

Anggota kelompok peternak sasaran dan peternak lain yang ada di luar kelompok diberi bimbingan jika menemui kendala dalam menjalankan usaha peternakan sapi terutama menyangkut materi materi penyuluhan yang sudah diberikan dan bimbingan tersebut dilaksanakan secara berkelanjutan sehingga kelompok peternak sasaran dan peternak yang ada didaerah kegiatan penyuluhan menjadi binaan dari tim.

\section{HASIL DAN PEMBAHASAN}

\section{Motivasi Kewirausahaan}

Materi yang diberikan terkait dengan peluang usaha peternakan, potensi ekonomi, nilai sosial yang diperoleh dan tidak lupa hambatan dan kendala dalam menjalankan usaha serta resiko kerugian yang akan diterima. Usaha peternakan sapi yang dijalankan oleh anggota kelompok ternak Makmur pada dasarnya merupakan usaha sampingan dengan tujuan hanya sebagai tabungan yang akan digunakan pada waktu tertentu seperti untuk keperluan sekolah anak dan juga untuk pesta pernikahan anak, sehingga tidak semua anggota kelompok yang menjalankan usaha ini dengan sungguh sungguh dan disamping itu jumlah ternak sapi yang dipelihara hanya dalam skala kecil, yaitu 1-3 ekor saja sehingga dengan demikian usaha ini belum bisa diandalkan untuk menopang seluruh perekonomian keluarga. Menurut Soekarwati(1988) ada dua ciri yang menonjol pada petani peternak yaitu jumlah kepemilikan ternak yang sedikit dan kecilnya pendapatan yang diterima. Semakin banyak jumlah ternak yang dimiliki biasanya pendapatan yang diperoleh juga semakin besar.

Respon peternak disaat penyampaian materi ini cukup tinggi, karena selama ini peternak belum mendapatkan gambaran sesungguhnya tentang potensi ekonomi dari usaha peternakan sapi yang mereka jalani, dan ada sebagian peternak yang pada prinsipnya menjalankan usaha atas dasar usaha yang turun temurun dari generasi sebelumnya.

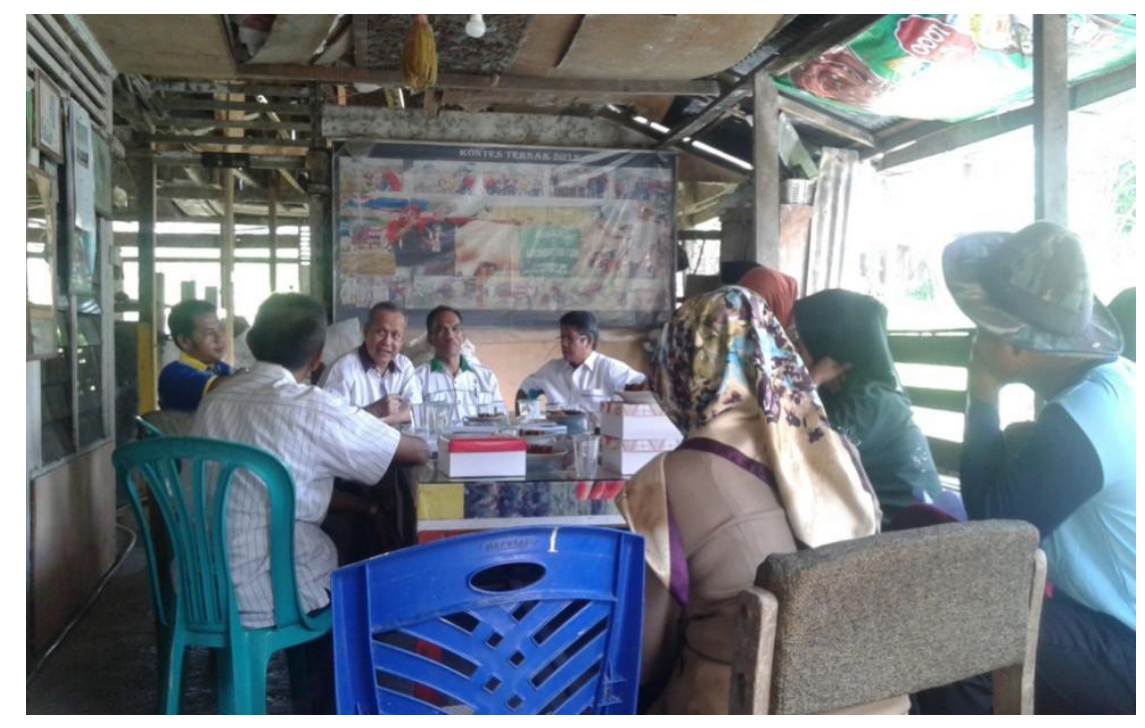

Gambar 1. Motivasi Usaha 


\section{Peningkatan Pengetahuan dan Keterampilan Tentang Pengaturan Reproduksi Ternak}

Sosialisasi dan demonstrasi tentang reproduksi ternak sapi dilakukan secara bersamaan, hal ini dilakukan agar anggota kelompok mitra dapat mengamati secara langsung objek atau materi yang disampaikan sehingga dengan proses yang demikian akan mudah dimengerti dan sekaligus akan meyakinkan peternak bahwa materi yang disampaikan relevan dengan keadaan yang sesungguhnya.

Materi yang diberikan adalah pengaturan reproduksi ternak sapi setelah melahirkan anak, tanda tanda birahi, Waktu birahi setelah melahirkan anak, waktu dikawinkan setelah melahirkan anak dan tindakan jika yang dilakukan jika birahi induk tidak datang. Tempat pelaksanaan kegiatan ini dilakukan di lokasi perkandangan peternak, hal ini dilakukan agar setelah dipaparkan secara teori, jika ada hal hal yang berkaitan dengan pengaturan reproduksi ternak ada yang menanyakan maka bisa langsung dijawab oleh narasumber dengan memberikan contoh pada ternak sapi yang ada diperkandangan tersebut.

Peternak berpartisipasi aktif dalam kegiatan ini, terbukti dengan tingkat kehadiran anggota yang tinggi disaat pelaksanaan kegiatan dan banyaknya pertanyaan pertanyaan yang di ajukan oleh peternak pada saat demontrasi. Bahkan pada kesempatan ini juga hadir penyuluh peternakan yang bertugas di daerah tersebut.

Aktifitas reproduksi setelah melahirkan sangat menentukan panjang pendeknya waktu kosong (tidak bunting) pada ternak. Semakin lama ternak tidak dikawinkan semakin lama kelahiran anak yang akan didapat, artinya semakin sedikit anak yang diperoleh sehingga pendapatan peternak juga akan berkurang. Waktu berahi muncul normal : 40-60 hari setelah melahirkan. Waktu kawin setelah melahirkan : setelah 45 hari

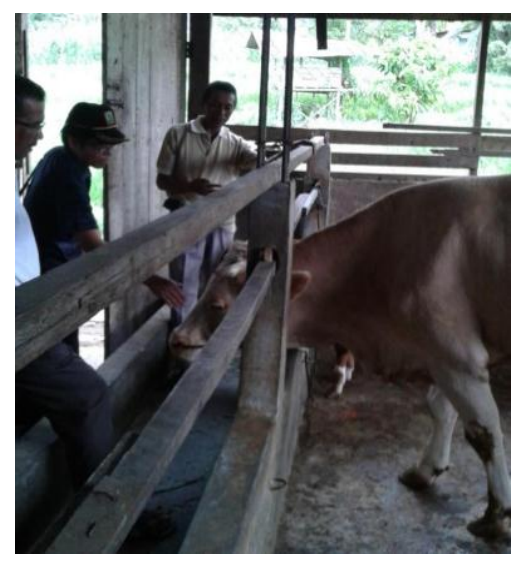

Gambar 2. Kegiatan Sosialisasi dan Demonstrasi pada Pengaturan Reproduksi Ternak Sapi

Tujuan mengawinkan sapi tidak terlalu cepat menyiapkan kondisi induk, sehingga dapat menampung anak berikutnya. Perkawinan terlalu cepat dapat menimbulkan keguguran terutama kalau ternak mendapat kurang perawatan seperti kurang pakan, anak akan terlahir kecil, dan ganguan lainya. Untuk mengetahui apakah kondisi tubuh ternak sudah bagus atau belum dapat dilihat dari tanda kondisi badan ternak tersebut. Untuk sapi bibit kondisi tubuh yang baik adalah mempunyai Body score minimalnya dengan nilai 2: tulang rusuknya terlihat tidak lebih dari 3 buah. Tindakan terhadap induk 
yang tidak muncul birahi:

1. Tidak muncul 90 hari : Sebaiknya dilakukan memisahkan anak dari induk

* Pemisahan secara permanen, anak harus mendapat pakan tambahan.

* Pemisahan sementara sampai induk berahi, anak perlu pakan tambahan

* Mengatur waktu menyusui 2-3 kali sehari,

2. Sapi yang tidak berahi setelah pelakuan di atas

Melakukan induksi berahi dengan menggunakan hormon, seperti hormon PGF2 alfa, sapi akan berahi dalam rentang waktu 2-5 hari.

3. Penanganan sapi yang tidak berhasil bunting setelah 3 kali kawin .

Sapi yang 3 kali kawin tidak bunting dikelompokkan mendapat gangguan reproduksi pada sapi-sapi tersebut perlu mendapat penanganan dengan membersikan uterus atau saluran peranakan sapi dengan meminta bantuan kepada mantri hewan atau dokter hewan.

Kegiatan ini sangat berimplikasi positif terhadap pengembangan usaha peternakan sapi dan memunculkan rasa optimis, terutama untuk anggota kelompok ternak Makmur karena dari aspek reproduksi ternak sapi pengetahuan dan keterampilan seperti itu belum pernah diperoleh sebelumnya, menurut anggota kelompok pengetahuan ini sangat penting untuk memperpendek jarak kelahiran, karena akhir akhir ini peternak merasakan bahwa jarak kelahiran (Calving Interval) terlalu panjang yaitu 1 ekor per 18 bulan 20 bulan sehingga secara ekonomis usaha peternakan yang mereka lakukan kurang menguntungkan. Hardjopranjoto (1995) Calving Interval sebaiknya tidak melebihi dari 400 hari. Gangguan ini dapat disebabkan oleh kekurangan makanan dan masalah reproduksi seperti bibit yang tidak berkualitas, perkawinan tidak tepat waktu, kegagalan deteksi berahi atau karena penyakit reproduksi. Pohan dan Thalib (2001) menyatakan bahwa kegagalan reproduksi sebagian besar ditentukan oleh faktor lingkungan yang terutama meliputi manajemen dan pemberian pakan yang buruk dan kurangnya peranan dokter hewan dalam menanggulangi penyakit reproduksi serta ketidak suburan (infertility) dan panjangnya periode anestrus.

\section{Introduksi Inovasi Pakan Urea Molases Blok (UMB) pada Peternak}

Introduksi inovasi UMB dilakukan dengan pendekatan penyuluhan demonstrasi, materi yang diberikan adalah manfaat pemberian UMB, bahan penyusun, komposisinya dan cara pembuatannya, setelah materi tersebut disampaikan kepada anggota kelompok mitra langsung di demonstrasikan cara pembuatannya mulai dari cara mencampur bahan, mengaduknya, mencampur dengan perekat, memasukan dalam cetakan, mengeluarkan dari cetakan sampai dengan terciptanya suatu produk UMB. 


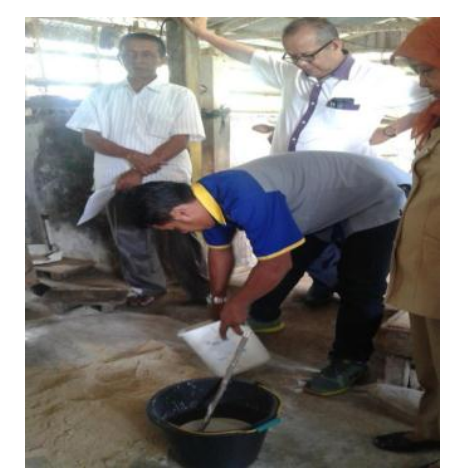

Gambar 3. Proses Pembuatan Urea Molases Block (UMB)

Berikutnya dilakukan demonstrasi cara pemberian, yaitu pemberian UMB yang sudah jadi kepada ternak sapi yang dimiliki oleh kelompok Makmur hal ini dilakukan karena UMB yang baru dibuat belum boleh diberikan secara langsung pada ternak karena harus di angin anginkan selama 3 hari di bawah sinar matahari. Pemberian UMB yang sudah jadi di gantungkan setinggi setengah meter dari tinggi ternak sapi, hal ini dilakukan agar UMB tersebut dapat bertahan lebih lama, yaitu 5 hari/ekor/1 kg UMB. Pada kesempatan itu dilakukan demonstrasi cara pemberian UMB pada ternak sapi yang dimiliki oleh Ketua kelompok ternak Makmur, karena pada kesempatan itu juga di distribusikan $20 \mathrm{~kg}$ UMB yang siap dikonsumsi oleh ternak kepada kelompok ternak sapi Makmur.

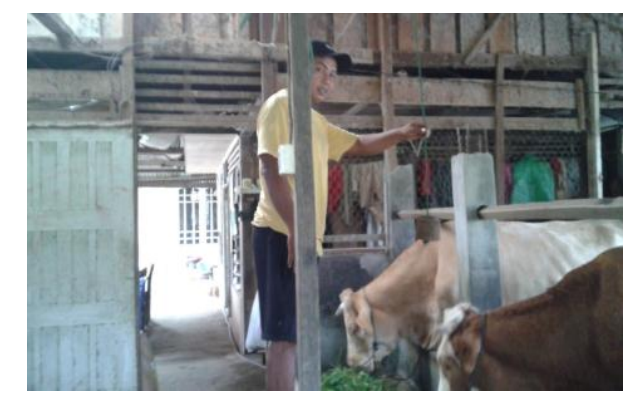

Gambar 4. Demonstrasi Cara Pemberian Urea Molases Block (UMB)

Partisipasi peserta cukup tinggi pada kegiatan ini, mulai dari bertanya soal kegunaan, cara pembuatan, bahan dan biaya pembuatan sampai dengan ikut serta membantu proses pebuatan dan cara pemberian pada ternak sapi. Tingkat kehadiran peserta juga lebih beraneka ragam, ada anggota kelompok ternak sapi Makmur, juga ada peternak lain yang berkeinginan datang sendiri, juga ada tenaga penyuluh sebanyak 2 orang dan juga mahasiswa peternakan sebanyak 5 orang.

\section{KESIMPULAN DAN SARAN}

\section{Kesimpulan}

Pengetahuan dan keterampilan anggota kelompok peternak Makmur mengalami peningkatan pada aspek reproduksi ternak, terutama dalam mengatur birahi induk setelah melahirkan anak. Kelompok sasaran mengetahui cara pembuatan dan cara 
pemberian pakan Urea Molases Block (UMB) untuk ternak sapi. Timbul semangat kewirausahaan pada anggota kelompok dan peternak lain yang bukan anggota kelompok di lokasi kegiatan .

\section{Saran}

Pemerintah melalui Badan penyuluh pertanian harus besinergi dengan kalangan akademisi untuk membantu mengembangkan usaha peternakan yang potensial. Perlu dilakukan kegiatan kegiatan yang serupa pada peternak dan kelompok peternak yang lain agar transfer ilmu maupun teknologi dapat konsisten berjalan. Khusus untuk peternak dan kelompok peternak yang terletak di lingkungan kampus wajib mendapat pembinaan berkelanjutan dari pihak akademisi kampus.

\section{DAFTAR PUSTAKA}

Anwar, S; Madariza, F dan Anas, A. 2009. Ilmu Penyuluhan Pertanian. Universitas Andalas, Padang.

Hardjopranjoto, S. 1995. Ilmu Kemajiran pada Ternak. Airlangga University Press, Surabaya.

Pohan A, Talib C. 2001. Efektivitas penyuntikan progesterone dan estrogen terhadap penanganan ketidak suburan pada sapi Bali dalam periode anestrus postpartum. Prosiding Seminar Nasional Teknologi Peternakan dan Veteriner, Pusat Penelitian dan Pengembangan Peternakan Bogor: 118-125.

Rogers EM, Schoemaker FF. 1995. Communication of Innovations: A Cross Cultural Approach. Revised Edition. The Free Press, New York.

Soekarwati, A., Soehardjo, J. Dillon dan Hardker. 1988. Prinsip Dasar Komunikasi Pertanian. Indonesia University Press, Jakarta.

Van Den Ban. A.W.,dan Hawkins, H.S. 1998. Penyuluhan Pertanian. Diterjemahkan oleh Agnes Dwina Herdiasti. Penerbit Kanisius, Yogyakarta. 